\title{
Clinical and Laboratory Findings in Patients with Leukocyte Adhesion Deficiency Type I: A Multicenter Study in Turkey
}

Ismail Yaz ( $\boldsymbol{\sigma}$ ismailyaz@hacettepe.edu.tr)

Hacettepe University Medical School https://orcid.org/0000-0001-5278-7456

Begum Ozbek

Hacettepe University Medical School

Hacer Neslihan Bildik

Hacettepe University Medical School

Cagman Tan

Hacettepe University Medical School

Sevil Oskay Halacli

Hacettepe University Medical School

\section{Elif Soyak Aytekin}

Hacettepe University Medical School

\section{Saliha Esenboga}

Hacettepe University Medical School

\section{Sukru Cekic}

Uludag University Medical School

\section{Sebnem Sara Kilic}

Uludag University Medical School

Ozlem Keskin

Gaziantep University Medical School

\section{Karin van Leeuwen}

University of Amsterdam

\section{Dirk Roos}

University of Amsterdam

\section{Deniz Cagdas}

Hacettepe University Medical School

\section{Ilhan Tezcan}

Hacettepe University Medical School 
Keywords: leukocyte adhesion deficiency type 1 (LAD-I), integrin, CD18, ITGB2, HSCT

Posted Date: March 24th, 2021

DOI: https://doi.org/10.21203/rs.3.rs-354758/v1

License: (c) (1) This work is licensed under a Creative Commons Attribution 4.0 International License. Read Full License

Version of Record: A version of this preprint was published at Clinical \& Experimental Immunology on August 5th, 2021. See the published version at https://doi.org/10.1111/cei.13645. 


\section{Abstract}

Leukocyte adhesion deficiency type I is rare primary immunodeficiency disorder characterized by mutations in the ITGB2 gene encoding CD18. We present clinical and immunological features of 15 patients with leukocyte adhesion deficiency type I (LAD-I). Targeted next-generation sequencing was performed with either a primary immunodeficiency gene panel comprising 266 genes or a small LADpanel consisting of five genes for genetic analysis. To measure the expression level of integrins on the leukocyte surface, flow cytometry analysis was performed. The median age of the patients at diagnosis was 3 (1-48) months. Eleven (73\%) of the 15 patients had LAD-I diagnosis in their first 6 months, and fourteen $(93 \%)$ patients had consanguineous parents. Delayed separation of the umbilical cord was present in $80 \%(n=12)$ of the patients in our cohort, whereas omphalitis was observed in $53 \%(n=8)$ of the patients. Leukocytosis with neutrophil predominance was observed in $73 \%(n=11)$ patients. Nine distinct variants in the ITGB2 gene in 13 of the 15 patients with LAD-I were characterized, of which two (c.305_306delAA and c.779_786dup) are novel homozygous mutations of ITGB2 . Four unrelated patients from Syria had a novel c.305_306delAA mutation that might be a founder effect for patients of Syrian origin. Four (27\%) patients underwent HSCT. Two of them died because of HSCT complications, and the other two are alive and well. Early differential diagnosis of the patients is critical in the management of the disease and genetic evaluation provides a basis for family studies and genetic counseling.

\section{Introduction}

Leukocyte adhesion deficiency type I (LAD-I) is a rare primary immunodeficiency with a prevalence of $1 / 100,000$ [1]. LAD-I is an autosomal recessively inherited disorder caused by mutations in ITGB2 gene encoding the $\beta$-chain (CD18) of $\beta 2$ integrins, located at chromosome 21 [2,3]. CD18 expression is essential for integrin dimerization, adhesion between leukocytes and endothelial cells, and processes such as extravasation and antimicrobial activity [4,5]. Defective or deficient CD18 impairs leukocyte mobilization into inflammation sites, causing tissues to become susceptible to long-lasting bacterial infections. The IL-23/IL-17 axis also becomes dysregulated, and wound healing is diminished [6].

Clinical manifestations of LAD-1 are delayed separation of the umbilical cord (UC), omphalitis and recurrent infections. Besides recurrent bacterial infections of skin and mucosal surfaces, gingivitis, periodontitis, otitis media and anemia secondary to severe infections are other symptoms $[7,8]$. Laboratory findings of LAD-1 patients are excessive neutrophilic leukocytosis in the circulation and reduced expression or absence of CD18, CD11a and CD11b expression on leukocytes. Hematopoietic stem cell transplantation (HSCT) is the only curative treatment option for patients with LAD-1 $[7,9]$.

Here, we report clinical manifestations, immunological findings, medical approach, and outcome of 15 patients diagnosed with leukocyte adhesion deficiency type I at 3 different medical centers in Turkey. Moreover, we highlight the importance of molecular testing with a next-generation sequencing (NGS) targeted primary immunodeficiency panel and/or Sanger sequencing for establishing the genetic diagnosis, which is essential for family studies and genetic counseling. 


\section{Methods}

\section{Patients}

Fifteen patients were diagnosed with LAD-I after referral to three Turkish clinical centers: Section of Pediatric Immunology, İhsan Doğramacı Children's Hospital, Hacettepe University, Ankara; Department of Pediatric Allergy and Immunology, Gaziantep University, Gaziantep; and Department of Pediatrics, Uludag University, Bursa. Demographical characteristics, clinical and laboratory findings of patients were recorded. Written informed consent was obtained from all participants.

\section{Flow Cytometry Analysis of Peripheral Blood Samples}

To measure the expression level of integrins on the leukocyte surface, flow cytometry analysis was performed with the following antibodies at optimal concentrations: anti-CD18-FITC and anti-CD11b-PC5. For the measurement of lymphocyte subgroups, peripheral blood mononuclear cells were stained with a mixture of the following antibodies at optimal concentrations: anti-CD3-FITC, anti-CD16-PE, anti-CD 56-PE, anti-CD45-PerCP-Cy ${ }^{\text {TM }}$ 5.5, anti-CD4-PE-Cy ${ }^{\text {TM }}$ 7, anti-CD19-APC and anti-CD8-APC-Cy7. Finally, data were analyzed by FACS Canto II flow cytometer and FACS Diva software (BD Biosciences)

\section{Genetic Analysis}

Genetic analysis was performed at Hacettepe University and at Sanquin Research Institute in Amsterdam, Netherlands.

Targeted next-generation sequencing was performed with either a primary immunodeficiency gene panel comprising 266 genes consisting of 5242 amplicons or a small LAD-panel consisting of five genes and 74 amplicons on the lon Torrent PGM platform. Disease-related mutations were determined following the filtration steps (EXAC, gnomAD, CADD, Mutation Taster, etc.). Ion Reporter 5.16 Bioinformatics Software was used for characterization and filtering of variants. Validations were performed by Sanger sequencing.

Exons of the ITGB gene were amplified under the following conditions: 1 cycle initial denaturation of 95 ${ }^{\circ} \mathrm{C}$ for $5 \mathrm{~min}, 35$ cycles of $95^{\circ} \mathrm{C}$ for $1 \mathrm{~min}, 58^{\circ} \mathrm{C}$ for $1 \mathrm{~min}, 72^{\circ} \mathrm{C}$ for $1 \mathrm{~min}$, and final elongation step of 72 ${ }^{\circ} \mathrm{C}$ for 10 min. Obtained PCR products were purified with Exo-SAP (Thermo Scientific, USA). PCR products were sequenced with the appropriate primers and BigDye ${ }^{\circledR}$ Terminator v3.1 Cycle Sequencing Kits (Applied Biosystems). The products were loaded on a 3130 Genetic Analyzer, and the results were analyzed with Sequencing Analysis v.5.2 software.

\section{Statistical Analysis}

Mean, median, minimum, and maximum values were calculated on IBM SPSS Statistics 23.

\section{Results}


The study included a total of 15 patients (10 males (67\%) and 5 females (33\%)) from 15 unrelated families. Ten (67\%) patients were Turkish and the other five were refugees of Syrian $(n=4,27 \%)$ and Iraqi $(n=1,7 \%)$ origin. The median symptomatic age of the patients was 21 (6-180) days (mean 41 days). The median age of the patients at diagnosis was 3 (1-48) months (mean 10 months). Eleven (73\%) patients had LAD-I diagnosis in their first 6 months. Fourteen (93\%) patients had consanguineous parents. Demographic characteristics of patients with LAD-1 are shown in Table 1.

\section{Infections}

Clinical findings observed in our patients in the follow-up are shown in Fig. 1. Delayed separation of the umbilical cord was present in $12(80 \%)$ patients in our cohort. Eight (53\%) patients presented with skin $(n=4,27 \%)$, soft tissue $(n=3,20 \%)$, perianal $(n=2,13.3 \%)$ or abdominal abscess $(n=1,7 \%)$. Viral infections such as EBV, CMV, Parainfluenza and/or Adenovirus were detected in $3(20 \%)$ patients. Only $2(13 \%)$ patients had signs of periodontal diseases such as gingivitis $(n=1,7 \%)$ and periodontitis $(n=1,7 \%)$. Diarrhea was present in $6(40 \%)$ patients. Gram-positive bacteria (Staphylococcus aureus, Staphylococcus epidermidis, Enterococcus faecium, Listeria monocytogenes) and gram-negative bacteria (Escherichia coli, Klebsiella pneumoniae) were isolated from cultures. Fungal infections (Aspergillus fumigatus, Candida albicans) were detected in $20 \%(n=3)$ of the patients.

\section{Complete Blood Count Analysis}

Leukocytosis was observed in 14 (93\%) patients at diagnosis, and leukocytosis with neutrophil predominance was observed in $11(73 \%)$ patients. The median leukocyte and neutrophil counts of the patients were $44.7(13.2-97.1) \times 10^{3} / \mu \mathrm{L}$ (mean $45.2 \times 10^{3} / \mu \mathrm{L}$ ) and $29.3(5.4-82.1) \times 10^{3} / \mu \mathrm{L}$ (mean $30.7 \times 10^{3} /$ $\mu \mathrm{L})$, respectively. Hemoglobin levels were lower than age-related reference values in $9(60 \%)$ patients. Platelet counts of $10(67 \%)$ patients were higher than reference values. C-reactive protein levels were higher than reference values in $12(80 \%)$ patients.

\section{CD18 Expression Levels and Lymphocyte Subgroup Analysis}

CD18 expression level was undetectable in 7 (47\%) patients. It was ranging from $1 \%$ to $8 \%$ in $8(53 \%)$ patients in our cohort. Cd11b expression was evaluated in 14 patients; it was undetectable in 5 patients (33\%) and varying between 1-45\% in 8 (53\%) patients. However, one patient showed 99\% CD11b expression on the cell surface, but CD18 expression of this patient was only $2 \%$. Percentage of patients according to absolute numbers of lymphocyte subgroups compared to age-related reference values in patients are shown in Fig. 2.

\section{Genetic Analysis}

Genetic analysis of the ITGB2 gene revealed 9 distinct mutations in 13 of the 15 patients with LAD-I (two patients had died before analysis). The same novel homozygous mutation, c.305_306delAA, was identified in all patients $(n=4)$ of Syrian origin, from unrelated families. c.779_786dup is a novel 
homozygous mutation identified in a patient. Homozygous c.382G >A, c.382G > T, c.533C > T, c.562C>T, c. $817 \mathrm{G}>\mathrm{A}$ and compound heterozygous c. $533 \mathrm{C}>\mathrm{T}$ and $\mathrm{c} .1777 \mathrm{C}>\mathrm{T}$ mutations were identified in 7 patients. All mutations identified in the patients are shown in Table 2 and in Fig. 3 , and the affected domains of CD18 are shown in Fig. 4.

\section{Treatment and Outcome}

Two (13\%) of the patients died because of infections. Four $(27 \%)$ patients underwent HSCT from a related donor. Two of these patients died because of HSCT complications, and the other two are alive and well. HLA typing has been done for nine patients. HSCT is planned for $3(20 \%)$ patients who have matched related donors. Six (40\%) of the patients have no matched related donor, and these patients are carefully being followed at our centers since their first admission.

\section{Discussion}

Leukocyte adhesion deficiency type I is a rare primary immunodeficiency that presents with typical clinical symptoms such as delayed umbilical cord separation and recurrent severe infections. The present report describes one of the largest comprehensive studies on clinical, immunological and molecular findings, and outcome of LAD-I patients from Turkey. Defects in CD18 expression in LAD-I lead to defective adhesion of leukocytes. Two forms of LAD-I have been described based on the level of CD18 expression on neutrophils: in severe form CD18 expression is $<2 \%$ of normal, and in moderate form CD 18 expression ranges from $2 \%$ to $30 \%$ [10]. Our patient cohort consisted of eleven patients with severe LAD-I and four patients with moderate LAD-I. Median age at the diagnosis of severe and moderate LAD-I cases were 3 (0.1-48) months and 5 (1-78) months, respectively, in a study from India [11]. The median age of our patients at diagnosis was $3(1-48)$ months, and $73 \%(n=11)$ of patients had LAD-I diagnosis in their first 6 months. Parental consanguinity ratio was reported to be as frequent as $51 \%$ (in severe LAD-I) in studies from Israel [7] and India [11]. According to the Turkish Statistical Institute, ratio of consanguineous marriages in Turkey was $23 \%$ in 2012. In our cohort, the consanguinity ratio was $93 \%$, indicating that autosomal recessive inheritance plays an important role, and consanguineous marriages contribute to occurrence of LAD-I.

In a study with 13 patients with LAD-I from Iran, all patients presented with leukocytosis and neutrophilia [12]. In our study leukocytosis was observed in 14 (93\%) patients, and leukocytosis with neutrophil predominance was observed in 11 (73\%) patients. In another study with 15 LAD-I patients from Iran, leukocyte counts showed persistent leukocytosis between 12.2 and $91 \times 10^{3} / \mu \mathrm{L}$ (median $\sim 29.1 \mathrm{x} 10^{3} / \mu \mathrm{L}$ ), with neutrophil ratio 31-90\% [13]. In our cohort, the median leucocyte and neutrophil counts of the

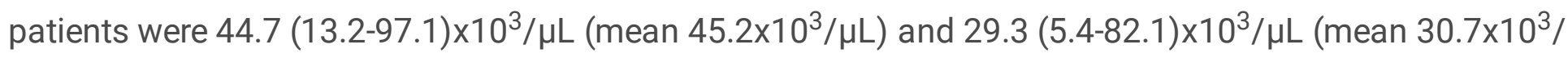
$\mu \mathrm{L})$, respectively. These data indicate that persistent leukocytosis is a significant feature of LAD-I.

Delayed umbilical cord detachment was found in $8(62 \%)$ out of 13 patients with LAD-I, and omphalitis was observed in $67 \%$ of the patients in a study from Israel [7]. Additionally, delayed separation of 
umbilical cord was observed in $5(\sim 63 \%)$ of 8 patients with LAD-I, and omphalitis was observed in only one patient in a study from Italy [14]. In the present study, signs of omphalitis were observed in approximately half of the patients, and delayed umbilical cord separation ratio was higher than in studies from Israel and Italy. This indicates that delayed umbilical cord detachment is one of the requisite components of LAD-I. De Rose et al. reported that patients with LAD-I present with numerous infections and autoimmune phenomena [14]. We did not observe autoimmune findings in our cohort except in a patient with alopecia areata. Periodontal manifestations such as oral ulcers, gingivitis and periodontitis have also been associated with LAD-I [2]. In the present study, periodontal destruction of the permanent dentition was observed in a 21-year-old male patient and gingivitis in a 4-year-old male patient. The reason for the low frequency of periodontal findings in our cohort might be the fact that most of the patients were in the infantile age group. In a study with 15 LAD-I patients from Iran, diarrhea was present in 5 patients, and hepatosplenomegaly was present in 4 patients [13]. Consistent with this study, diarrhea and hepatosplenomegaly were present in 6 and 3 patients, respectively, in our cohort.

Wolach et al. reported that 11 out of 18 patients (61\%) with LAD-I had chronic anemia [7]. In our cohort, $60 \%(n=9)$ of the patients had anemia, possibly related to chronic infections. Most of our patients $(n=10$, $67 \%$ ) had thrombocytosis, which may have occurred secondary to an underlying inflammatory condition.

We have characterized 9 distinct variants in the ITGB2 gene in 13 patients with LAD-I, of which 2 have not been reported previously. Interestingly, four unrelated patients from Syria had a novel c.305_306delAA mutation that might be a founder effect for LAD-I patients of Syrian origin. A homozygous novel c.779_786dup mutation was identified in one patient, and the CD18 expression in this patient was $1 \%$. Homozygous c.382G $>\mathrm{A}, \mathrm{c} .382 \mathrm{G}>\mathrm{T}, \mathrm{c} .533 \mathrm{C}>\mathrm{T}, \mathrm{c} .562 \mathrm{C}>\mathrm{T}, \mathrm{c} .817 \mathrm{G}>\mathrm{A}$ and compound heterozygous c. $1777 \mathrm{C}>\mathrm{T}$ and $\mathrm{c} .533 \mathrm{C}>\mathrm{T}$ mutations identified in 7 patients in our cohort were reported previously [1520]. Large chromosomal deletions, including a whole ITGB2 gene deletion and exonic deletions, were reported in several studies [3,20-23]. In our cohort, one patient harbored a large deletion (exon 12_14), which is probably the same as one reported previously [3]. The patient homozygous for the large exon 12_14 deletion had no detectable CD18 expression.

Cabanillas et al. reported a case of leukocyte adhesion deficiency type I in a 4-year-old girl with CD18 expression levels exceeding $30 \%$ but with a completely non-functional protein [24]. In our cohort, CD18 expression on cell surface of a patient homozygous for the novel c.305_306delAA variant was absent (clone: L130, BD). Interestingly, in repeated testing of the same patient, CD18 expression was found at higher expression levels (clone: 7E4, Beckman Coulter). This variability is related to characteristics of monoclonal antibody binding and incomplete protein expression. However, the clinical features and genetic findings of the disease were consistent with LAD-I. In any case, CD11a, CD11b and CD11c expression on the cell surface of the patient was $0 \%, 1 \%$ and $7 \%$, respectively. On the other hand, in the other three homozygous patients with the novel c.305_306delAA variant, CD18 expression was only $1 \%$. It must be considered that the results of flow cytometry analysis of CD18 expression in different laboratories may vary. CD18 expression level should be analyzed repeatedly by using different antibody 
clones in patients with clinical findings compatible with LAD-I and by considering the genetic cause and the truncated protein structure.

Gene therapy trials for patients with LAD-I are ongoing [25], but HSCT is the only curative treatment option of LAD-I currently available. HSCT success was 2/4 in our study.

We must consider leukocyte and neutrophil counts of patients presenting with delayed detachment of the umbilical cord, omphalitis, and severe infections. Additionally, characterization of CD18 levels by flow cytometry analysis is essential for diagnosis, but molecular characterization of LAD-I is also important in terms of disease confirmation, therapeutic approach, prognosis, and follow-up of patients. Early diagnosis of the patients is critical in the management of the disease and genetic evaluation is essential for family studies and genetic counseling.

In conclusion, we report the clinical manifestations, immunological findings, treatment, and outcome of 15 patients diagnosed with LAD-I. Parental consanguinity was very high in the current study. Also, delayed umbilical cord detachment was observed more frequently than in previous reports. Additionally, two novel mutations were reported, extending the molecular spectrum of LAD-I.

\section{Declarations}

\section{Acknowledgements}

The authors thank the patients and their families for their collaboration and participation. This project was supported by Scientific and Technological Research Council of Turkey (Project Number: 315S125).

\section{Ethical Approval}

The study complied with the Declaration of Helsinki and was approved by the ethics committee of Hacettepe University.

\section{Consent to Participate/Consent to Publish}

All participants provided written and informed consent. All co-authors give their formal written Consent to Publish prior to the submission of each version of the paper.

\section{Authorship Contributions}

All authors were involved in drafting the manuscript or revising it critically for intellectual content; all authors approved the final version to be published. IY performed experiments, collected the data, and wrote the paper. BO performed experiments, contributed to data collection. CT and SOH contributed to data or analysis tools. HNB, ESA and SE contributed to follow-up of the patients. SC, SSK and OK contributed to data collection and follow-up of the patients. KvL performed genetic analysis. DR supervised the study and corrected the manuscript. DC contributed to data collection and follow-up of the patients, and supervised the study. IT conceived, designed, and supervised the study. 


\section{Funding Information}

This project was supported by Scientific and Technological Research Council of Turkey (Project Number: 315S125).

\section{Disclosure of Conflicts of Interest}

The authors declare that they have no conflict of interests.

\section{Availability of data and materials}

The data that support the findings of this study are available on request from the corresponding authors, IY, IT.

\section{References}

[1] A.A. Justiz Vaillant, F. Ahmad, Leukocyte Adhesion Deficiency, StatPearls Publishing, 2020. https://www.ncbi.nlm.nih.gov/books/NBK539770/.

[2] S. Hanna, A. Etzioni, Leukocyte adhesion deficiencies, Ann. N. Y. Acad. Sci. 1250 (2012) 50-55. https://doi.org/10.1111/j.1749-6632.2011.06389.x.

[3] E. van de Vijver, A. Maddalena, Ö. Sanal, S.M. Holland, G. Uzel, M. Madkaikar, M. de Boer, K. van Leeuwen, M.Y. Köker, N. Parvaneh, A. Fischer, S.K.A. Law, N. Klein, F.I. Tezcan, E. Unal, T. Patiroglu, B.H. Belohradsky, K. Schwartz, R. Somech, T.W. Kuijpers, D. Roos, Hematologically important mutations: Leukocyte adhesion deficiency (first update), Blood Cells, Mol. Dis. 48 (2012) 53-61. https://doi.org/10.1016/j.bcmd.2011.10.004.

[4] D.C. Anderson, F.C. Schmalsteig, M.J. Finegold, B.J. Hughes, R. Rothlein, L.J. Miller, S. Kohl, M.F. Tosi, R.L. Jacobs, T.C. Waldrop, A.S. Goldman, W.T. Shearer, T.A. Springer, The Severe and Moderate Phenotypes of Heritable Mac-1, LFA-1 Deficiency: Their Quantitative Definition and Relation to Leukocyte Dysfunction and Clinical Features, J. Infect. Dis. 152 (1985) 668-689. https://doi.org/10.1093/infdis/152.4.668.

[5] S. Schmidt, M. Moser, M. Sperandio, The molecular basis of leukocyte recruitment and its deficiencies, Mol. Immunol. 55 (2013) 49-58. https://doi.org/10.1016/j.molimm.2012.11.006.

[6] A. Etzioni, Leukocyte-adhesion deficiency - UpToDate, (2017) 1-24.

https://www.uptodate.com/contents/leukocyte-adhesion-deficiency.

[7] B. Wolach, R. Gavrieli, O. Wolach, T. Stauber, O. Abuzaitoun, A. Kuperman, Y. Amir, P. Stepensky, R. Somech, A. Etzioni, Leucocyte adhesion deficiency-A multicentre national experience, Eur. J. Clin. Invest. 49 (2019) 1-17. https://doi.org/10.1111/eci.13047. 
[8] S.G. Tangye, W. Al-Herz, A. Bousfiha, T. Chatila, C. Cunningham-Rundles, A. Etzioni, J.L. Franco, S.M. Holland, C. Klein, T. Morio, H.D. Ochs, E. Oksenhendler, C. Picard, J. Puck, T.R. Torgerson, J.L. Casanova, K.E. Sullivan, Human Inborn Errors of Immunity: 2019 Update on the Classification from the International Union of Immunological Societies Expert Committee, J. Clin. Immunol. 40 (2020) 24-64. https://doi.org/10.1007/s10875-019-00737-x.

[9] E. Almarza Novoa, S. Kasbekar, A.J. Thrasher, D.B. Kohn, J. Sevilla, T. Nguyen, J.D. Schwartz, J.A. Bueren, Leukocyte adhesion deficiency-l: A comprehensive review of all published cases, J. Allergy Clin. Immunol. Pract. 6 (2018) 1418-1420.e10. https://doi.org/10.1016/j.jaip.2017.12.008.

[10] E.S. Harris, A.S. Weyrich, G.A. Zimmerman, Lessons from rare maladies: Leukocyte adhesion deficiency syndromes, Curr. Opin. Hematol. 20 (2013) 16-25.

https://doi.org/10.1097/MOH.0b013e32835a0091.

[11] P.M. Kambli, U.A. Bargir, R.M. Yadav, M.R. Gupta, A.D. Dalvi, G. Hule, M. Kelkar, S. Sawant-Desai, P. Setia, N. Jodhawat, N. Nambiar, A. Dhawale, P. Gaikwad, S. Shinde, P. Taur, V. Gowri, A. Pandrowala, A. Gupta, V. Joshi, M. Sharma, K. Arora, R.K. Pilania, H. Chaudhary, A. Agarwal, S. Katiyar, S. Bhattad, S. Ramprakash, R. CP, A. Jayaram, V. Gornale, R. Raj, R. Uppuluri, M. Sivasankaran, D. Munirathnam, H.P. Lashkari, M. Kalra, A. Sachdeva, A. Sharma, S. Balaji, G.M. Govindraj, S. Karande, R. Nanavati, M. Manglani, G. Subramanyam, A. Sampagar, I. CK, P. Gutha, S. Kanakia, S.P. Mundada, V. Krishna, S. Nampoothiri, S. Nemani, A. Rawat, M. Desai, M. Madkaikar, Clinical and Genetic Spectrum of a Large Cohort of Patients With Leukocyte Adhesion Deficiency Type 1 and 3: A Multicentric Study From India, Front. Immunol. 11 (2020) 1-7. https://doi.org/10.3389/fimmu.2020.612703.

[12] S. Teimourian, M. De Boer, D. Roos, A. Isaian, M.H. Bemanian, S. Lashkary, M. Nabavi, S. Arshi, A. Nateghian, S. Sayyahfar, F. Sazgara, G. Taheripak, E. Alipour Fayez, Genetic Analysis of 13 Iranian Families with Leukocyte Adhesion Deficiency Type 1, J. Pediatr. Hematol. Oncol. 41 (2019) E3-E6. https://doi.org/10.1097/MPH.0000000000001221.

[13] M. Movahedi, N. Entezari, Z. Pourpak, S. Mamishi, Z. Chavoshzadeh, M. Gharagozlou, B. MirSaeeid-Ghazi, M.R. Fazlollahi, F. Zandieh, M.H. Bemanian, A. Farhoudi, Clinical and laboratory findings in Iranian patients with leukocyte adhesion deficiency (study of 15 cases), J. Clin. Immunol. 27 (2007) 302307. https://doi.org/10.1007/s10875-006-9069-4.

[14] D.U. De Rose, S. Giliani, L.D. Notarangelo, V. Lougaris, A. Lanfranchi, D. Moratto, B. Martire, F. Specchia, A. Tommasini, A. Plebani, R. Badolato, Long term outcome of eight patients with type 1 Leukocyte Adhesion Deficiency (LAD-1): Not only infections, but high risk of autoimmune complications, Clin. Immunol. 191 (2018) 75-80. https://doi.org/10.1016/j.clim.2018.03.005.

[15] N. Parvaneh, S. Mamishi, A. Rezaei, N. Rezaei, B. Tamizifar, L. Parvaneh, R. Sherkat, B. Ghalehbaghi, S. Kashef, Z. Chavoshzadeh, A. Isaeian, F. Ashrafi, A. Aghamohammadi, Characterization of 
11 new cases of leukocyte adhesion deficiency type 1 with seven novel mutations in the ITGB2 gene, J. Clin. Immunol. 30 (2010) 756-760. https://doi.org/10.1007/s10875-010-9433-2.

[16] S. Matsuura, F. Kishi, M. Tsukahara, H. Nunoi, I. Matsuda, K. Kobayashi, T. Kajii, Leukocyte adhesion deficiency: Identification of novel mutations in two japanese patients with a severe form, Biochem. Biophys. Res. Commun. 184 (1992) 1460-1467. https://doi.org/10.1016/S0006291X(05)80047-6.

[17] A.L. Back, W.W. Kwok, D.D. Hickstein, Identification of two molecular defects in a child with leukocyte adherence deficiency, J. Biol. Chem. 267 (1992) 5482-5487. https://doi.org/10.1016/s00219258(18)42791-3.

[18] F. Lorusso, D. Kong, A.K.A. Jalil, C. Sylvestre, S.L. Tan, A. Ao, Preimplantation genetic diagnosis of leukocyte adhesion deficiency type I, Fertil. Steril. 85 (2006) 494.e15-494.e18.

https://doi.org/10.1016/j.fertnstert.2005.03.092.

[19] N. Hogg, M.P. Stewart, S.L. Searth, R. Newton, J.M. Shaw, S.K.A. Law, N. Klein, A novel leukocyte adhesion deficiency caused by expressed but nonfunctional $\beta 2$ integrins Mac-1 and LFA-1, J. Clin. Invest. 103 (1999) 97-106. https://doi.org/10.1172/JCl3312.

[20] D. Roos, C. Meischl, M. De Boer, S. Simsek, R.S. Weening, Ö. Sanal, I. Tezcan, T. Güngör, S.K.A. Law, Genetic analysis of patients with leukocyte adhesion deficiency: Genomic sequencing reveals otherwise undetectable mutations, Exp. Hematol. 30 (2002) 252-261. https://doi.org/10.1016/S0301472X(01)00782-2.

[21] T.H. Bernard Cher, H.S. Chan, G.F. Klein, J. Jabkowski, G. Schadenböck-Kranzl, O. Zach, X. Roca, S.K. Alex Law, A novel 3' splice-site mutation and a novel gross deletion in leukocyte adhesion deficiency (LAD)-1, Biochem. Biophys. Res. Commun. 404 (2011) 1099-1104.

https://doi.org/10.1016/j.bbrc.2010.12.124.

[22] M. Fiorini, G. Piovani, R.F. Schumacher, C. Magri, V. Bertini, E. Mazzolari, L. Notarangelo, L.D. Notarangelo, S. Barlati, ITGB2 mutation combined with deleted ring 21 chromosome in a child with leukocyte adhesion deficiency, J. Allergy Clin. Immunol. 124 (2009) 1356-1358. https://doi.org/10.1016/j.jaci.2009.07.058.

[23] B. Sun, Q. Chen, X. Dong, D. Liu, J. Hou, W. Wang, W. Ying, X. Hui, Q. Zhou, H. Yao, J. Sun, X. Wang, Report of a Chinese Cohort with Leukocyte Adhesion Deficiency-I and Four Novel Mutations, J. Clin. Immunol. (2019). https://doi.org/10.1007/s10875-019-00617-4.

[24] D. Cabanillas, L. Regairaz, C. Deswarte, M. García, M.E. Richard, J.L. Casanova, J. Bustamante, L. Perez, Leukocyte Adhesion Deficiency Type 1 (LAD1) with Expressed but Nonfunctional CD11/CD18, J. Clin. Immunol. 36 (2016) 627-630. https://doi.org/10.1007/s10875-016-0322-1. 
[25] Gene Therapy for Patients With Leukocyte Adherence Deficiency (Follow-Up of Phase 1 Trial), Clin. Identifier NCT00023010. (2001). https://clinicaltrials.gov/ct2/show/NCT00023010.

\section{Tables}

Table 1. Demographic characteristics of patients with LAD-1

\begin{tabular}{|c|c|c|c|c|c|}
\hline & Gender & Origin & $\begin{array}{c}\text { Symptomatic Age } \\
\text { (Days) }\end{array}$ & $\begin{array}{c}\text { Age at Diagnosis } \\
\text { (Months) }\end{array}$ & $\begin{array}{c}\text { Parental } \\
\text { Consanguinity }\end{array}$ \\
\hline P1 & M & Turkish & 180 & 14 & + \\
\hline P2 & M & Turkish & 60 & 2 & + \\
\hline P3 & F & Turkish & 30 & 3 & + \\
\hline P4 & F & Turkish & 60 & 3 & + \\
\hline P5* & F & Turkish & 12 & 3 & + \\
\hline P6* & M & Turkish & 45 & 5 & + \\
\hline P7 & M & Turkish & 21 & 5 & + \\
\hline P8 & F & Syrian & 7 & 1 & + \\
\hline P9 & M & Syrian & 20 & 1 & + \\
\hline P10 & M & Syrian & 18 & 12 & + \\
\hline P11 & M & Iraqi & 30 & 4 & + \\
\hline P12 & F & Syrian & 105 & 48 & + \\
\hline P13 & M & Turkish & 10 & 48 & + \\
\hline P14* & M & Turkish & 6 & 1 & + \\
\hline P15* & M & Turkish & 16 & 2 & \\
\hline
\end{tabular}

*deceased

Table 2. Mutations in ITGB2 and CD18 expression in patients.

\begin{tabular}{|c|c|c|c|c|c|c|}
\hline Patients & Zygosity & Exon & cDNA & Amino acid & Novelty & $\begin{array}{c}\text { CD18 } \\
\text { Expression }\end{array}$ \\
\hline P1 & $\begin{array}{c}\text { Compound } \\
\text { heterozygous }\end{array}$ & $\begin{array}{c}6 \text { and } \\
13\end{array}$ & $\begin{array}{c}\text { c.533C>T and } \\
\text { c.1777C>T }\end{array}$ & $\begin{array}{c}\text { Pro178Leu and } \\
\text { Arg593Cys }\end{array}$ & $\begin{array}{c}\text { Both } \\
\text { reported }\end{array}$ & $8 \%$ \\
\hline P2 & Homozygous & $12 \_14$ & c.1413_2080del & - & Reported & $0 \%$ \\
\hline P3 & Homozygous & 6 & c.562C>T & Arg188* & Reported & $0 \%$ \\
\hline P4 & Homozygous & 7 & c.779_786dup & Thr263Cysfs*20 & Novel & $1 \%$ \\
\hline P5 & Homozygous & 7 & c.817G >A & Gly273Arg & Reported & $0 \%$ \\
\hline P6 & Homozygous & 6 & c.533C>T & Pro178Leu & Reported & $2 \%$ \\
\hline P7 & Homozygous & 6 & c.533C>T & Pro178Leu & Reported & $0 \%$ \\
\hline P8 & Homozygous & 4 & c.305_306delAA & Lys102Serfs*39 & Novel & $1 \%$ \\
\hline P9 & Homozygous & 4 & c.305_306delAA & Lys102Serfs*39 & Novel & $1 \%$ \\
\hline P10 & Homozygous & 4 & c.305_306delAA & Lys102Serfs*39 & Novel & $1 \%$ \\
\hline P11 & Homozygous & 4 & c.382G $>$ T & Asp128Tyr & Reported & $3 \%$ \\
\hline P12 & Homozygous & 4 & c.305_306delAA & Lys102Serfs*39 & Novel & $0 \%$ \\
\hline P13 & Homozygous & 4 & c.382G $>$ A & Asp128Asn & Reported & $2 \%$ \\
\hline P14 & n/a & n/a & n/a & n/a & n/a & $0 \%$ \\
\hline P15 & n/a & n/a & n/a & n/a & n/a & $0 \%$ \\
\hline
\end{tabular}


*n/a: not available.

\section{Figures}

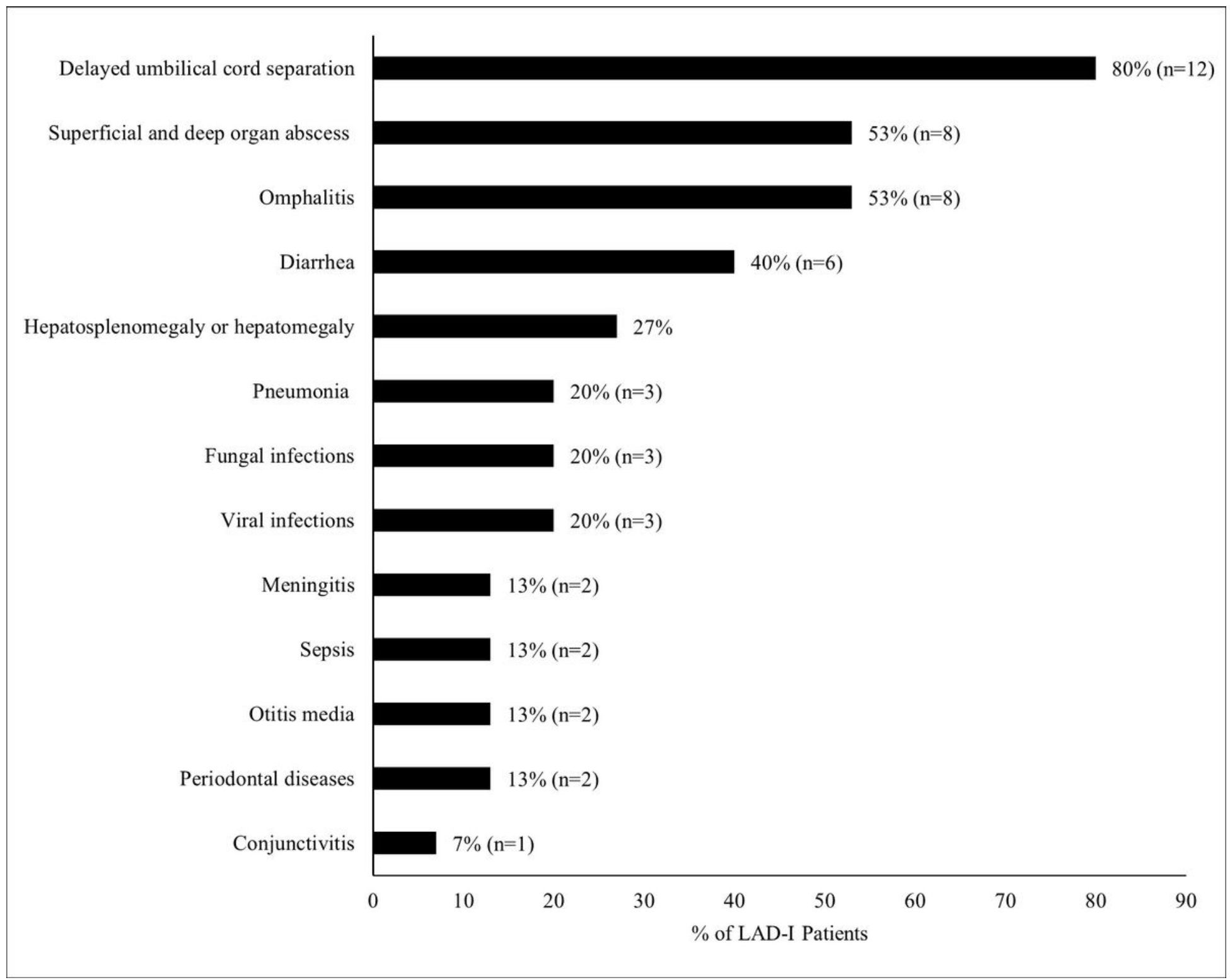

Figure 1

Clinical findings in patients with LAD-1. * Some of the patients have more than one clinical finding. The total number is not the number of patients. 


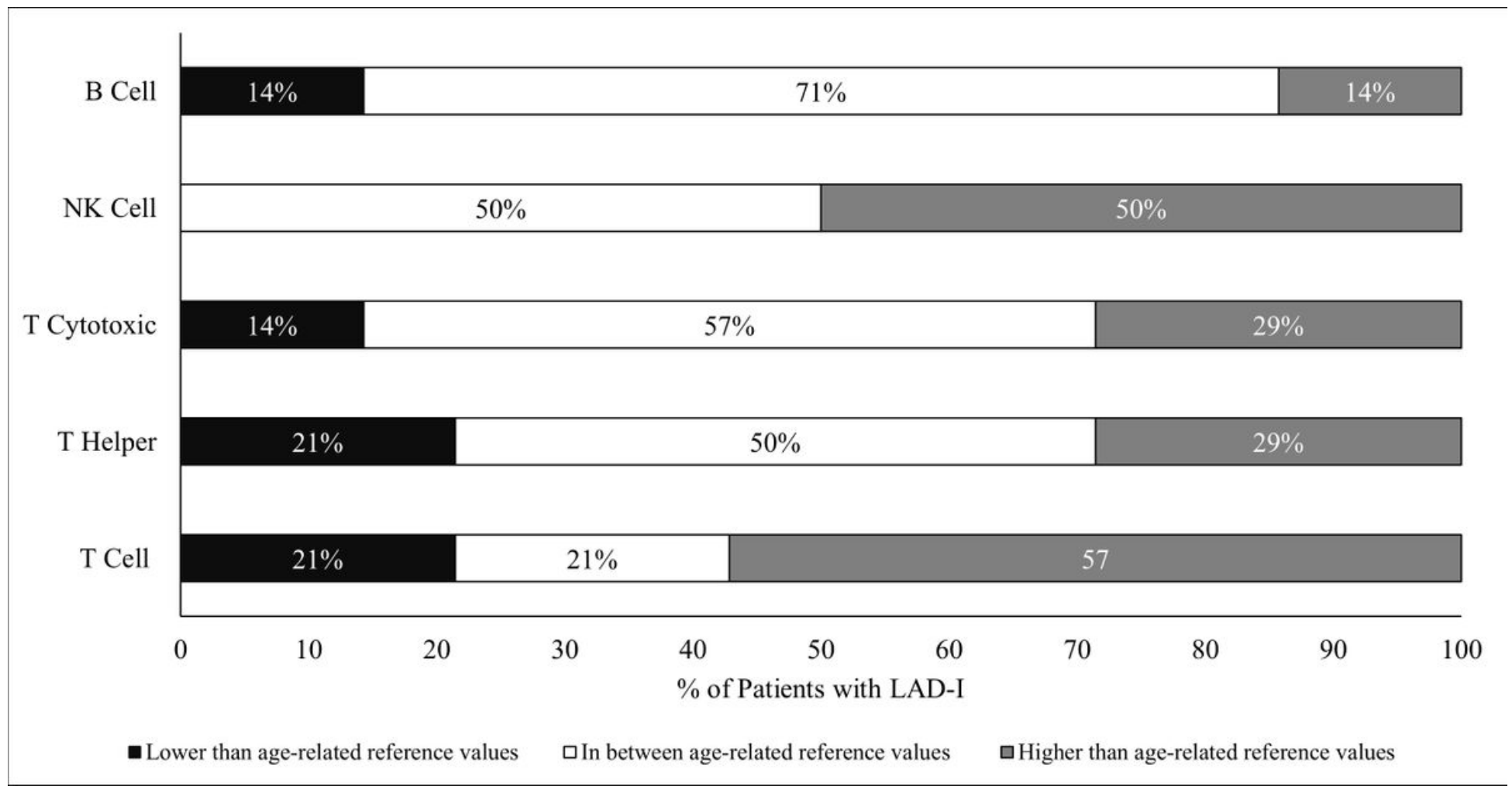

\section{Figure 2}

Percentage of patients according to absolute numbers of lymphocyte subgroups compared to age-related reference values.

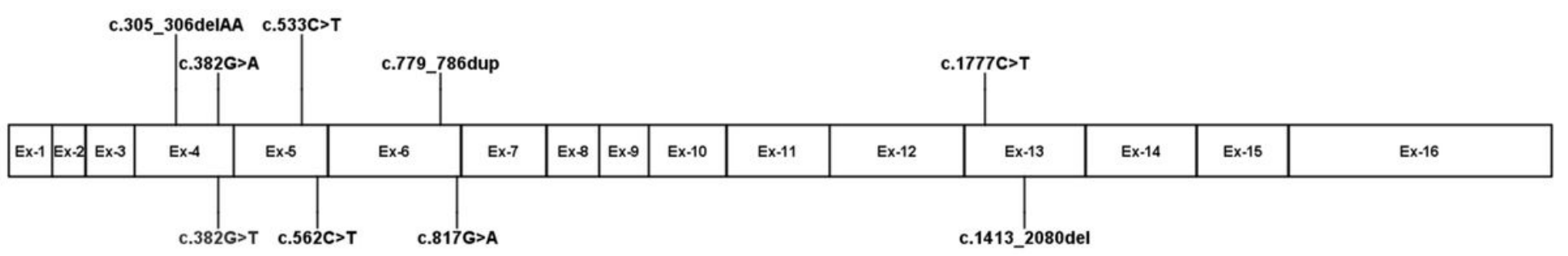

\section{Figure 3}

CDNA of ITGB2 gene and positions of mutations. *The figure was drawn according to NCBI Reference Sequence: NM_000211.5.

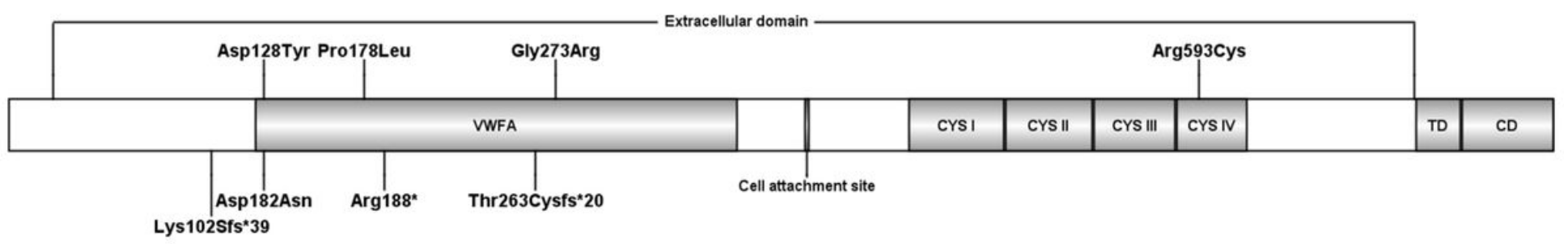

\section{Figure 4}

Domain structure of the CD18 protein encoded by ITGB2 and positions of mutations. VWFA, Von Willebrand factor type A domain; CYS, Cysteine-rich tandem repeat; TD, Transmembrane domain; CD, 
Cytoplasmic domain.

Page 15/15 